Article

\title{
Solving the Difficulties and Challenges Facing Construction Based on Concurrent Engineering in Yemen
}

\author{
Sabrinaji Dahmas, Zhongfu Li and Sha Liu * \\ Department of Construction Management, Dalian University of Technology, Dalian 116024, China; \\ dahmas@mail.dlut.edu.cn (S.D.); lizhongfu@dlut.edu.cn (Z.L.) \\ * Correspondence: sophie_liu@dlut.edu.cn
}

Received: 2 May 2019; Accepted: 30 May 2019; Published: 4 June 2019

check for updates

\begin{abstract}
Due to the highly competitive commercial environment in the market in Yemen at present, the construction industry in Yemen, like other industries, is under pressure to reduce product development time and overall project costs, improve product quality, and satisfy customers. To keep pace with the competitive environment of the market in Yemen, most enterprises tend to adopt the best and new technologies, new management concepts and philosophies such as Total Quality Management (TQM) and concurrent engineering (CE) to achieve improvements in the process of product development. In this paper, the problem of fragmentation brought by the serial engineering in construction in Yemen is discussed firstly. Then, the integration process and CE adoption by the construction industry in Yemen are explained for enabling construction agencies in Yemen to improve the development process of their projects and to solve the current fragmentation problems such as the lack of communication, adversarial culture and the lack of customer focus, which allows the construction process to improve and become more effective and efficient.
\end{abstract}

Keywords: fragmentation problem; concurrent engineering (CE); construction industry in Yemen; traditional engineering

\section{Introduction}

The new developments in Information Technology (IT) and information systems have created a very competitive environment for all organizations in all sectors including the construction industry. Due to this situation, construction organizations must adopt some developments to support their business environment accompanied by the implementation of new management concepts such as concurrent engineering (CE) [1]. CE can make the construction industry more integrated and less fragmented, as well as improving construction product quality, reducing the construction project life cycle and the total construction product cost [2]. CE is a systematic approach to the parallel and integrated design of products and their associated processes, including manufacturing and support. The basic concept of CE is to consider all the factors of the product life cycle (including quality, cost, schedule and user requirements) at the beginning of product development, which can shorten the time to market and improve quality while controlling costs [3]. The implementation of CE in the construction industry requires a series of changes, which can be divided into two main aspects: the managerial and human aspect and the technological aspect. The implementation of CE can be divided into four dynamic stages: preparing for change; creating a team environment; team bonding and sustaining CE [4]. This paper discusses the current problems in the construction industry in Yemen and how to benefit from the implementation of concurrent engineering in the construction industry in Yemen to solve the problems caused by the use of serial engineering in the construction industry, and the integration of systems and teams to support CE execution. 


\section{Current Issues in the Construction Industry in Yemen}

Yemen is a developing country, where problems in construction projects often lead to extra costs and delays. Studies show that in some developing countries, the actual cost of construction projects exceeds the original contract price by $30 \%$ when the project is completed $[5,6]$. The successful execution of construction projects, keeping them within the estimated cost and the prescribed schedules, primarily depends on the existence of an efficient construction industry which is capable of sustained growth and development to cope with the requirements of social and economic development and to utilize the latest technology in planning and execution [7-9].

According to a report by the Yemeni Ministry of Public Works and Road, in the first seven months of the civil war in Yemen, the estimated cost of damage to infrastructure was more than \$14 billion [10]. A survey by the Yemeni Ministry of Education also indicated that 1671 schools suffered damage, 387 needed major reconstruction, and 250 were destroyed in the civil war. The estimated cost of the damage was more than $\$ 300$ million [9]. Due to the intensity of the civil war, reports can only assess the damages in the cities of Sana'a, Aden, Taiz, and Zanzibar, and data collection was stopped in October 2015. These data found an estimated $\$ 3.6$ billion in damages to private homes. The total cost of rebuilding the damaged power facilities in the four cities is estimated at $\$ 335$ million, most of which goes to repairing damaged power plants [9].

Yemen is a developing country where project management often relies on traditional methods in most industrial sectors, including the construction industry. The construction industry in Yemen is an essential sector in the national economy of the country [11-13]. The majority of the construction projects in Yemen has been carried out in the past within expensive and costly construction and design practices, resulting in low-quality buildings [7,14]. The construction projects in Yemen are the fourth largest employer of the workforce in the country, amounting to $9-10 \%$ of the working population, and the average annual growth rate of the sector is approximately $5.4 \%$, which is effectively contributing to the economic growth of Yemen [8]. However, it is also very late in adopting new developments in IT and modern management practices such as $\mathrm{CE}$, which can improve the competitive environment of the construction industry in Yemen in terms of cost reduction, non-delay in the delivery of projects, and the enhancement of product quality. Therefore, the construction companies in Yemen are required to develop the methods of operations by means of using the current project management methodologies to improve the construction process and overcome the defects found in traditional engineering. The most common problems from the fragmentation of the construction processes are a lack of sense of identity, promoting a adverserial culture, lack of communication between contractors and designers during the design stage, and a lack of feedback loops or coordination between the design and construction process, etc. $[15,16]$. The most critical issues in the construction process and its impact on the project will be discussed in the next section.

The most common problem of applying traditional engineering in the construction industry is how to separate the design from the rest of the construction process. In essence, the common contract strategy is based on the lack of sense of identity and the promotion of adversarial culture or coordination between design and construction [17]. This method usually leads to inefficiency, which is caused by increased project complexity, increased project cost, an inability to control the project period, etc., during construction. Figure 1 shows how traditional engineering works in the construction industry in Yemen. 


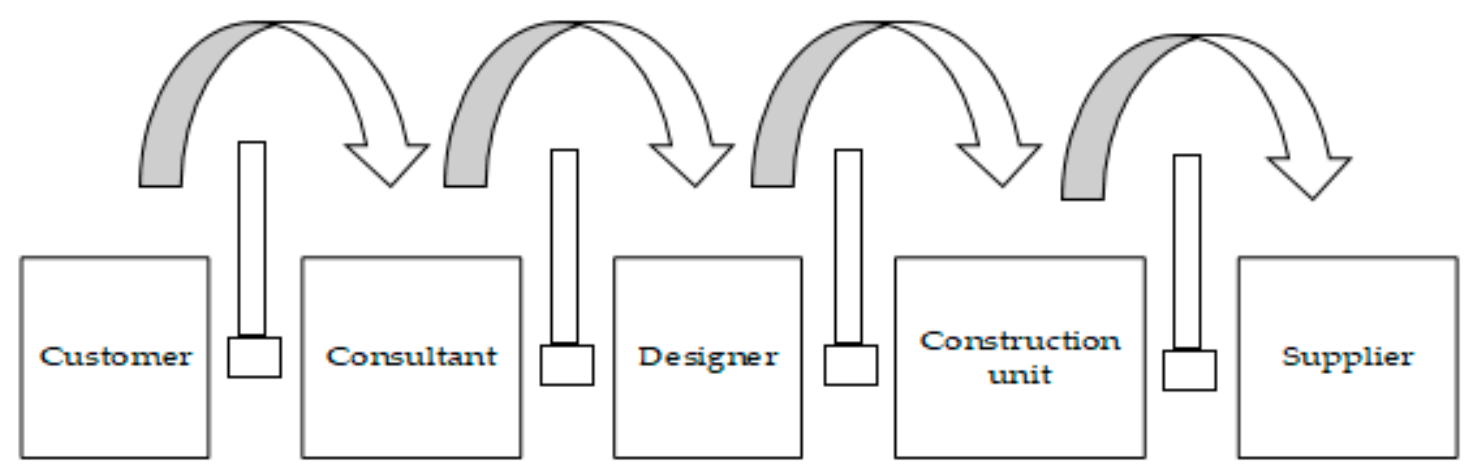

Figure 1. The over-the-wall approach.

The report by Egan [18] was highly critical of the current nature of the construction process, which is often served as a barrier to the use of the skills and knowledge of all the project partners effectively during the design and planning of the project. Many previous studies have also suggested that other experts should be involved in the first stage of project design, such as designers, mechanical engineers, electrical engineers, building technicians, and other facility management experts $[19,20]$. Therefore, the structure of the current construction industry in Yemen contains the potential for conflict when participants try to transfer risks to others [15], e.g., the goals of the designer and builder are different during the design and construction stages: the designer wants a practical design that reflects his philosophy, while the builder wants to design a buildable product with limited risks [15].

In the regulatory context, the fragmentation of organizational work in the construction industry in Yemen, which occurs under the application of traditional engineering, is the primary cause of friction and mistrust between the contracting parties. The fragmented traditional approach will also create some related problems such as [21]:

Lack of communication [22]: Many studies and research in the construction industry have confirmed that the lack of communication between different teams and disciplines is a major problem faced by the construction industry [23-25]. Communication between contractors, subcontractors, and designers is often limited at the early stage of design [26]. Many studies have concluded that the flow of information between stakeholders and different disciplines in the construction industry is minimal [23-25]. Also, researchers found that the level of communication between the main contractor and subcontractors, as well as the interaction between different disciplines within the framework of traditional engineering, is shallow, especially at the first stage of the design process [27]. As mentioned above, the most successful design of large multi-disciplinary project requires extensive coordination among the various project teams to ensure that all the inter-disciplinary interactions such as architects, civil engineers, and quality registrars are facilitated and all the parties are kept abreast of the continuous changes in the state of the project. The problem of poor communication leads to inefficiency, delay, and cost changes that will have an impact on project coordination and project schedule. Additionally, the design and construction processes in traditional engineering hinder the integration of design and construction, reducing the opportunity for the influence of design decisions by professionals and contractors as well.

Adversarial Culture: The construction industry is known as a complex industry, whose essence is based on temporary relationships between different parties. As explained above, the problem of fragmentation in the construction industry is not only in the relations of the project but also in the operations of the project itself, whether using traditional methods or modern methods of construction. For example, the current form of the construction industry contains many potential conflict points where participants transfer risks to others [15]. The issue is clearly shown among all the project teams and may be caused by a simple misunderstanding or assumptions that are mainly due to the current traditional method that is based on the separation between design and construction. In general, the construction industry is fragmented, uncoordinated and full of lack of understanding between different 
parties [28], hence it is focused on non-customers, and is inefficient and expensive, and requires a capable system for the parties to meet together to discuss problems.

Lack of customer Focus: In the use of traditional engineering in the construction industry, the problem of rarely focusing on the client arises, that is characterized by the lack of client involvement in the first stage of design and this lack of influence on design decisions in turn leads to the possibility of producing a product which does not meet customer requirements. Ignoring a focus on the customer leads to ignoring the real market requirements, and this negatively impacts product marketing in the construction industry [29]. A previous study criticized the performance of this industry and defined the fragmentation and separation of design and construction as the main obstacle to improve the current situation of the construction industry [30]. To improve market conditions and work to meet the customer demands, this study finds that the construction industry needs more integration and synchronization among all the parties involved in the project [15].

\section{Necessity and Feasibility of the Implementation of CE in Construction}

\section{1. $C E$}

$\mathrm{CE}$ is one of the new methods that began in the late 20th century and has great potential in reducing project development time, reducing product cost and increasing product quality. This approach integrates all components of the project, including the technology and tools used in the development process [17]. The ultimate goal of CE is to satisfy the customers in terms of the ability to provide a low-cost product, reduce time to market and increase product quality. However, the path towards the adoption of $\mathrm{CE}$ in the construction industry still faces many challenges [31,32]. The earliest definition of CE is "Concurrent engineering is a systematic approach to integrate and concurrent design of products and related processes, including manufacturing and support. This approach aims to enable developers to consider all elements of the product life cycle from concept to placement from the beginning, including quality, cost, schedule and user needs" [33].

$\mathrm{CE}$ is the embodiment of the principle of integration, which is the early involvement of all the stakeholders (the design stage). CE focuses on the stage of design and gets things done correctly in the first instance to avoid rework and redesign, and future problems in other stages of the production process. It shows the importance of integrating project participants from various disciplines and employees of different specialties in the project, as well as customers, suppliers and others, so that stakeholders from the early stages of design can participate in decision-making and influence the design [34]. This leads to the adoption of a multidisciplinary approach. The environment in CE, which is characterized by cooperation, communication and integration, distinguishes it from traditional methods. It ensures the rapid collection of information on issues and works more efficiently [35]. Figure 2 summarizes the concept of CE:

GOALS

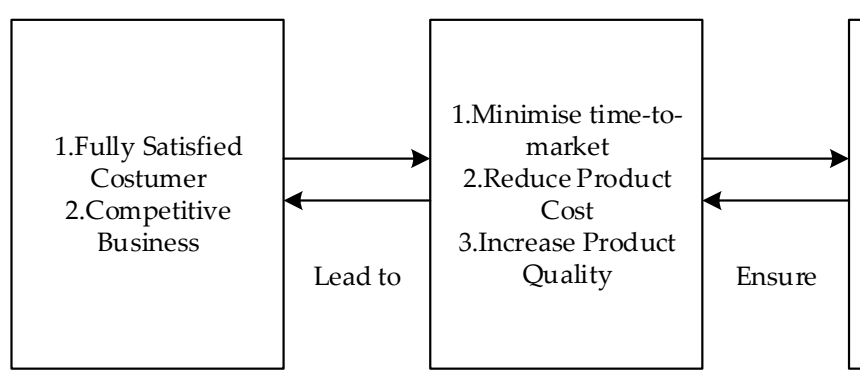

Figure 2. A framework for understanding

TOOLS AND TECHNIQUES

\section{STRATEGY}

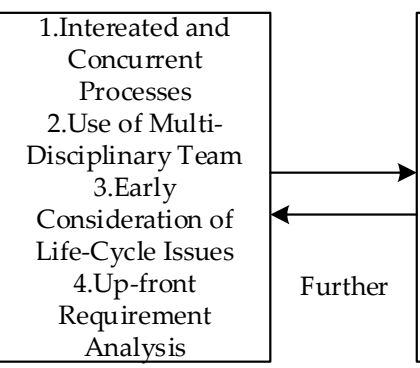

1.Various Tools 2.Agent

\&Knowledge-Based Techniques 3.CAD/CAM, CAE, etc., 


\section{2. $C E$ in the Construction Industry}

The construction industry today relies on new tools and techniques that differ from traditional operating methods, such as BIM and CE, to improve and minimize project development time. However, the problems and barriers inherent in the construction industry mentioned above lead to stagnation in the process of improvements, such as the fragmentation of the project, the separation of different disciplines, and the hostile environment $[33,36]$. The success of CE in the manufacturing industry is one of the main catalysts for adopting it in the construction industry, due to the similarity between the processes of these two industries. Many studies are based on the assumption that construction can be considered as a manufacturing process [31]. Furthermore, the goals and objectives of CE directly address the challenges and problems currently facing the construction industry (as shown in Table 1) [37]. The importance of construction as a manufacturing process depends primarily on the similarity between the manufacturing and construction industries [35]. The most important points of similarity between these two industries are [38,39]:

1. The aim is to produce products that provide service and satisfaction to the customer;

2. Both co-handle raw materials and assemble many different pre-manufactured components in the final products;

3. Both industries are faced with similar problems the most important of which is the high cost of correcting design errors due to delayed variables, the misuse of resources and insufficient information management;

4. Both take advantage of frequent processes in designing and manufacturing their products.

Table 1. The rationale for the adoption of concurrent engineering in the construction industry.

\begin{tabular}{ll}
\hline Need to Change in the Construction Industry & Goals and Principles of CE \\
\hline $\begin{array}{l}\text { The need for change in construction is due to the } \\
\text { non-competitive nature of this industry, the inability } \\
\text { to satisfy the customer in full regard to costs, quality } \\
\text { and time. }\end{array}$ & $\begin{array}{l}\text { The primary goals and principles of concurrent } \\
\text { engineering include customer satisfaction, providing } \\
\text { a competitive environment, reducing product } \\
\text { development time, cost, and quality improvement. }\end{array}$ \\
\hline $\begin{array}{l}\text { Integration and coordination are considered in the } \\
\text { construction process as one of the most important } \\
\text { strategies to solve the problem of fragmentation in } \\
\text { the construction industry. }\end{array}$ & $\begin{array}{l}\text { The adoption of the concept of concurrent } \\
\text { engineering in the construction industry facilitates } \\
\text { the integration of members of the product } \\
\text { development team and the manufacturing process, } \\
\text { thus improving the product development process. }\end{array}$ \\
\hline $\begin{array}{l}\text { The strategies that are emerging to promote the } \\
\text { construction process are inadequate, as they only } \\
\text { address one side of the problem. }\end{array}$ & $\begin{array}{l}\text { CE provides a framework not only for integrating } \\
\text { construction processes but also for the various tools } \\
\text { and technologies used in the process. }\end{array}$ \\
\hline
\end{tabular}

\subsection{The Potential Benefits of Adopting the Principles of CE in the Construction Industry in Yemen}

Many researchers have proven the benefits of the adoption of concurrent engineering in the construction industry $[23,33,40,41]$. This method improves the performance of the project because of the factors that have been explained previously [31,42]. The benefits of this method in manufacturing are realized, but similar results in the construction industry are scarce, despite much empirical evidence. This includes the advantages of simultaneous reduction and even elimination of non-value-based activities, thus producing a more precise design, all through the involvement of all the stakeholders in the project, multi-disciplinary teams, and the multi-functional teams. There are many potential benefits that the construction industry in Yemen can experience from implementing the characteristics of $C E$ in their organizations $[3,43]$. The application of simultaneous engineering principles in the construction industry in Yemen helps demolish the "invisible wall" that separates the different functional organizations and makes them function as a robust cooperative team that shares the goals and objectives of the project. This is done by the participation of all the different disciplines 
in the first stage of the project (design). Another significant benefit is the ability of construction companies to reduce and control the project life cycle and the ability to deliver the project in time. This problem is more common in the traditional construction industry. The use of CE in the construction industry in Yemen makes the public environment of the industry less adversarial, more cooperative and coordinated. The implementation of such a method will increase confidence between different disciplines and stakeholders and the ability to produce a product of high quality and with less cost, and is done by reducing the chances of re-work and minimizing the time of arrival of the product to the market and good control of the delivery dates of the project. It is also essential to make the construction industry more competitive. The implementation of this method in the construction industry in Yemen makes this industry environmentally friendly through its ability to reduce waste.

\section{Application of CE in Construction Industry}

\subsection{The Goal for CE in the Construction Industry}

$\mathrm{CE}$ is the product of a competitive production system in the increasingly global market. Its application is to acquire competitive advantages and better meet the needs of customers, so enterprises can shorten product development time, improve product quality, reduce product production costs, enhance after-sales services and protect the environment. That is, the competition around Time, Quality, Cost, Service, and Environment (TQCSE). The concept of CE is applied in the construction industry to ensure project quality, reduce construction costs, shorten the construction cycle and improve customer satisfaction.

\subsection{Construction Organizational Structure Model Based on CE}

The application of the construction organizational structure of $\mathrm{CE}$ is more systematic, which breaks through the boundaries among different organizational units within the organization, centers on construction of a new flattening cross-departmental, cross-disciplinary and multifunctional organization pattern. During construction project management, the parallel organization teams should integrate personnel from different fields including developer, architectural design, structural design, construction unit, consulting unit, project supervision, and property management, and even include the building material supplier, component manufacturer and representatives of future owners. The application of the team organization pattern in the parallel process greatly enhances effective information exchange and cooperation among the personnel of different departments in the whole life cycle of the engineering project and makes possible the consideration of problems in the whole life cycle of the project in the design stage.

Under the guidance of $\mathrm{CE}$, team members have the same working goals and methods in the stage of production and construction, and also take some responsibilities, including all parties involved in the whole cycle process of the project, such as the developer, owners, and the designer. The team is composed of groups with various specialties, integrating various disciplines and different knowledge structures, so as to create an efficient team with high comprehensive quality and to become the subject of $\mathrm{CE}$ in construction projects.

Unlike the previous production management patterns, the organizational team pattern in $\mathrm{CE}$ reduces problems in the later stage of the project due to a lack of consideration of the interests of some participants in the early stage of project development. Meanwhile, the organizational structure of the parallel team is conducive to considering the interests of all the parties involved in the project in the early stage of project construction, so that the implementation process of the whole project and the final construction products can meet the interests of all the participants better through joint decision making. Therefore, the organizational structure of construction project based on CE (as shown in Figure 3) is proposed. The organizational pattern has the following functions: 
1. It significantly improves the information transparency of the project and enhances the efficiency and validity of information exchange among the project participants.

2. It is helpful for the project participants to know the construction situation of the project in time and improve the integrity and parallelism of the real estate project development.

3. It is more conducive to the timely update of project information, thus avoiding project delay caused by information delay and shortening the time of information transmission and processing.

4. The concurrent organization team exchanges information with each other based on the project communication and coordination information platform, thus forming a very nice working atmosphere, and successfully applying the concept of $\mathrm{CE}$ in the construction process of the project.

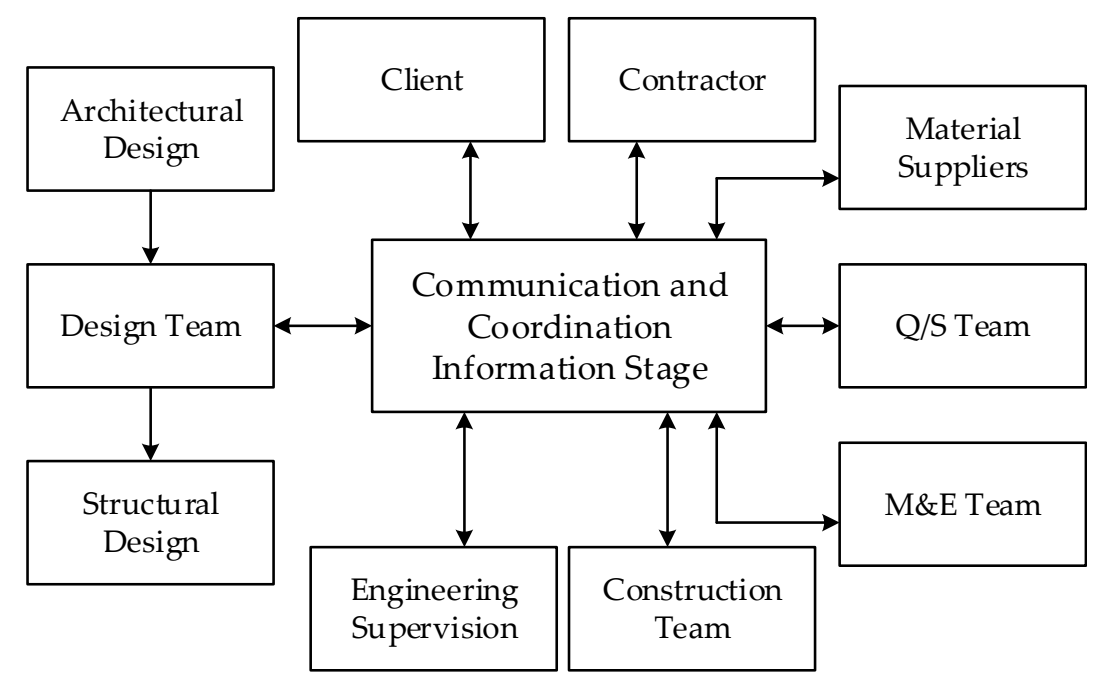

Figure 3. Organizational structure of the construction project based on the concept of CE.

\subsection{Construction Workflow Management System Based on CE}

The construction process of development patterns in original construction projects follows serial steps, with very clear boundaries between stages and unidirectional information flow and sometimes unrealistic schemes considered in the design stage, which result in some difficulties in the subsequent construction process. These construction problems can only be shown in a certain stage, causing the developer complaints and rework. Construction projects based on CE are required to establish a new organizational structure system, and traditional serial engineering is no longer applicable in a parallel development pattern, so it is very important to create a new work process suitable for a parallel development pattern. In this study, a diagram of the management and control system for a construction project is shown, which integrates the concept of CE (as shown in Figure 4). 


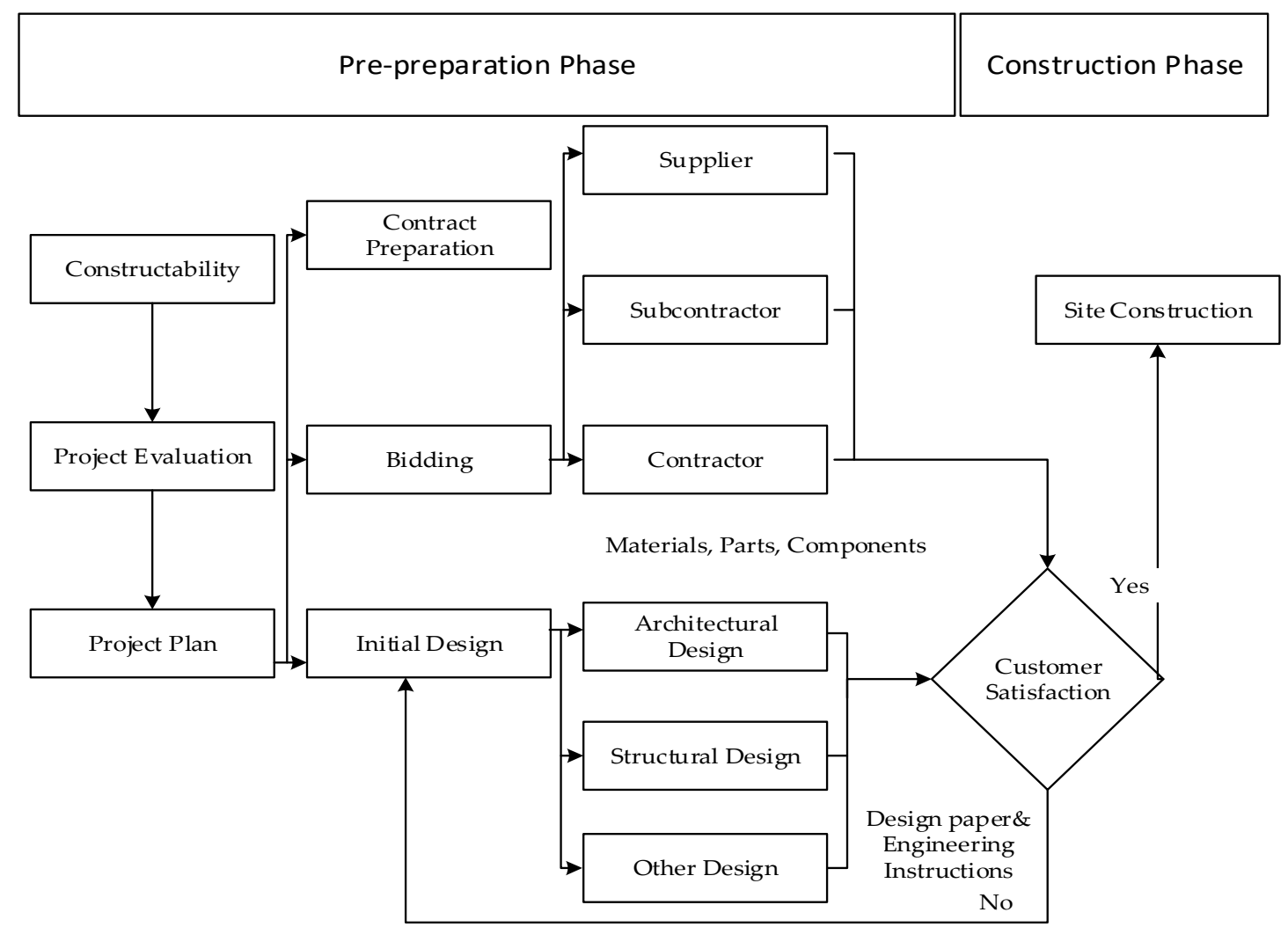

Figure 4. Diagram of management pattern and control system for a concurrent engineering construction project.

"The CE development pattern" takes the concept of CE as the core starting point to consider the problems existing in the production process. Therefore, compared with the traditional plans and control methods of serial engineering projects, it has the following features:

1. Comprehensively considering the sharing of information resources among different departments and units of the project, thus greatly improving the efficiency of project construction and effectively reducing construction cost.

2. The concept of $\mathrm{CE}$ uses information flow to control material flow to ensure the smooth progress of the project and increases the management efficiency of the enterprise.

3. The concept of CE conforms to the needs of increasing amounts of project management information and accurately describes real-time information, dynamics and the interconnection of different departments and units of the project.

There are still many barriers to the uptake of $\mathrm{CE}$ and consideration needs to be given to overcome them to ensure successful CE implementation, such as, low awareness and understanding of the concept of $\mathrm{CE}$, lack of trust between team members, and the conservative nature of the construction industry in Yemen. These barriers can be overcome by periodic training for all workers in the construction industry, providing a platform for collaborative work between different disciplines and stakeholders, promoting collaborative work and sharing knowledge, as well as the adoption of established information and communications technologies [41].

\section{Conclusions}

Over the past three years, Yemen has gone through a devastating war that has almost destroyed the country's infrastructure, from hospitals, schools, universities, factories, roads, etc. After reaching an agreement to end the war, Yemen needs to implement the use of $\mathrm{CE}$ as a quick reconstruction of all its infrastructure. As previously discussed, many studies and statistics show that the nature of the 
current construction industry in Yemen depends on the traditional method (fragmentation), which depends primarily on the separation of professionals during the design and construction periods. One of the disadvantages of this method is its inefficiency during the construction stage by increasing the complexity of the project, increasing rework, producing a hostile environment, lack of communication among the stakeholders, and the inability to control the life cycle of the project. That is to say that the construction industry in Yemen needs to use new methods and techniques to develop and improve its work and make it more competitive. Many new technologies such as CE proved successful in manufacturing. By regarding the construction activity as a manufacturing process, the application of $\mathrm{CE}$ in the construction industry makes this sector less fragmented, more integrated and more collaborative.

This paper illustrates the basic principles of $\mathrm{CE}$ and its applicability in the construction industry. The contribution of this research in the construction industry is to adopt new methods such as CE to reduce the problems existing in this industry such as lack of communication, adversarial culture and lack of customer Focus. The application of the concept of CE in the construction industry is a new method, encouraging a change of culture and practices in the integration of different project processes. The aim of using CE in the construction industry is not only to introduce new methods and work practices but also to improve efficiency such as reducing construction time and rework. As shown in the objectives and benefits of $\mathrm{CE}$, it has the ability to change the construction industry in many aspects, including improving competition, quality, customer satisfaction, and reducing cost and time.

As mentioned above, there are many benefits to implementing the concept of concurrent engineering in the construction industry in Yemen, yet implementing this concept is not easy. Before the adoption of the concept of $\mathrm{CE}$, construction industry organizations should assess the readiness of these organizations to implement this concept. In the next study, we will focus on some of the construction industry organizations in Yemen and evaluate their willingness to apply the concept of CE. In light of these results, we can give suggestions and solutions to these organizations to achieve full readiness to implement the concept of CE and ensure the success of this model in the construction industry in Yemen.

Author Contributions: Conceptualization, S.D. and Z.L.; Formal analysis, S.D. and S.L.; Funding acquisition, S.D.; Investigation, S.L. and Z.L.; Methodology, S.D.; Software, S.D.; Validation, S.D. and S.L.; Writing - original draft, S.D.; Writing - review \& editing, S.L.

Funding: National Thirteenth-Five-year Research Program of China (No. 2018YFC0705901).

Conflicts of Interest: The authors declare no conflict of interest. The funders had no role in the design of the study; in the collection, analyses, or interpretation of data; in the writing of the manuscript, and in the decision to publish the results.

\section{References}

1. Khalfan, M.; Raja, N. Improving Construction Process through Integration and Concurrent Engineering. Constr. Econ. Build. 2012, 5, 58-66. [CrossRef]

2. Kamara, J.M.; Anumba, C.J.; Evbuomwan, N.F.O. Developments in the implementation of concurrent engineering in construction. Int. J. Comput. Integr. Des. Constr. 2000, 10, 10.

3. Ahmad, S.B.S.; Svalestuen, F.; Andersen, B.; Torp, O. A Review of Performance Measurement for Successful Concurrent Construction. Procedia - Soc. Behav. Sci. 2016, 226, 447-454. [CrossRef]

4. Khalfan, A. Benchmarking and readiness assessment for concurrent engineering in construction. This item is held in Loughborough University' s Institutional Repository. Available online: https://dspace.lboro.ac.uk/ (accessed on 1 September 2001).

5. Sultan Basel, M.; Kajewski Stephen, L. The Yemen construction industry: Readying the industry for the successful implementation of sustainability. In Proceedings of the International Conference on Smart and Sustainable Built Environment, Brisbane, Australia, 19-21 November 2003.

6. Al-Momani, A.H. Construction cost prediction for public school buildings in Jordan. Constr. Manag. Econ. 1996, 14, 311-317. [CrossRef]

7. Sultan, B. Housing construction costs in Yemen: Affordability \& purchasing power. Yemen Times 2008, 6, 6-7. 
8. Ahmad, S.A.; Issa, U.H.; Farag, M.A.; Abdelhafez, L.M. Evaluation of risk factors affecting time and cost of construction projects in Yemen. Int. J. Manag. 2013, 4, 168-178.

9. Issa, U.H.; Hassona, F.A.; EL-Sawah, H.M. Risk identification and assessment for the Egyptian water projects, economic and management of water in Arab world and Africa, In Proceedings of the 1st International Conference, Assuit University, Assiut, Egypt, 18-19 November 2009.

10. Cordesman, A.H. The War in Yemen: Hard Choices in a Hard War. Available online: https://www.csis.org/ analysis/war-yemen-hard-choices-hard-war (accessed on 9 May 2017).

11. Carapico, S. Civil Society in Yemen: The Political Economy of Activism in Modern Arabia; Cambridge University Press: Cambridge, UK, 2007.

12. Lichtenthäler, G. Political Ecology and the Role of Water: Environment, Society and Economy in Northern Yemen; Routledge: Abingdon, UK, 2017.

13. El Mallakh, R. The Economic Development of the Yemen Arab Republic (RLE Economy of Middle East); Routledge: Abingdon, UK, 2014.

14. Al-Sabahi, M.H.; Al-Hamidi, A.A.; Ramly, A.; Rejab, K.M. Exploring criteria and critical factors for governmental projects implementation in Yemen: A case study. J. Surv. Constr. Prop. 2014, 5, 1-17. [CrossRef]

15. Nawi, M.N.M.; Baluch, N.; Bahauddin, A.Y. Impact of fragmentation issue in construction industry: An overview. Available online: http://docplayer.net/19192761-Impact-of-fragmentation-issue-in-constructionindustry-an-overview.html (accessed on 14 September 2014).

16. Nawi, M.N.M.; Lee, A.; Azman, M.N.A.; Kamar, K.A.M. Fragmentation issue in Malaysian industrialised building system (IBS) projects. J. Eng. Sci. Technol. 2014, 9, 97-106.

17. Gann, D.M. Construction as a manufacturing process? Similarities and differences between industrialized housing and car production in Japan. Constr. Manag. Econ. 1996, 14, 437-450. [CrossRef]

18. Egan, J. Rethinking construction accelerating change-a consultation paper by the strategic forum for construction. Nat. Acad. Scie. Eng. Med. 2002, 5, 34.

19. Latham. Constructing the team. Constr. Team 1994, 7, 956-963.

20. Nelson, M.M.L. The Applicability of I2i as A Supply Chain Management Tool in Facilities Management. Ph.D. Thesis, University of Salford, Manchester, UK, 2004.

21. Evbuomwan, N.F.; Anumba, C.J. An integrated framework for concurrent life-cycle design and construction. Adv. Eng. Softw. 1998, 29, 587-597. [CrossRef]

22. Ghazali, Y.E.; Lefebvre, É.; Lefebvr, L.A. RFID-Enabled Materials Management in the Industrial Construction Supply Chain. Proc. 5th WSEAS Int. Conf. Commun. Inf. Technol. 2014, 7, 167.

23. Anumba, C.J.; Baugh, C.; Khalfan, M.M. Organisational structures to support concurrent engineering in construction. Ind. Manag. Data Syst. 2002, 102, 260-270. [CrossRef]

24. Odeh, A.M.; Battaineh, H.T. Causes of construction delay: Traditional contracts. Int. J. Proj. Manag. 2002, 20, 67-73. [CrossRef]

25. Nawaz, T.; Shareef, N.A.; Ikram, A.A. Cost performance in construction industry of Pakistan. Ind. Eng. Lett. 2013, 3, 19-33.

26. Gray, C.; Hughes, W. Building Design Management; Routledge: Abingdon, UK, 2007.

27. Mohamad, M.I. The application of concurrent engineering philosophy to the construction industry. Ph.D. Thesis, Loughbrgh University, Loughbrgh, UK.

28. Alashwal, A.M.; Rahman, H.A.; Beksin, A.M. Knowledge sharing in a fragmented construction industry: On the hindsight. Sci. Res. Essays 2011, 6, 1530-1536.

29. Walker, P. Procurement, contracts and conditions of engagement within a concurrent engineering context. In Concurrent Engineering in Construction Projects; Routledge: Abingdon, UK, 2006.

30. Dulaimi, M.F.; YLing, F.Y.; Ofori, G.; Silva, N.D. Enhancing integration and innovation in construction. Build. Res. Inf. 2002, 30, 237-247. [CrossRef]

31. Anumba, C.J.; Kamara, J.M. Concurrent engineering in construction. In Construction Innovation and Process Improvement; Wiley: Hoboken, NJ, USA, 2012; p. 277.

32. Love, P.E.; Gunasekaran, A.; Li, H. Concurrent engineering: A strategy for procuring construction projects. Int. J. Proj. Man. 1998, 16, 375-383. [CrossRef]

33. Anumba, C.J.; Duke, A.K. Telepresence Environment for Concurrent Lifecycle Design and Construction; Taylor \& Francis: Abingdon, UK, 2007; p. 218. 
34. Wolden, S. The Application of Concurrent Engineering in Infrastructure Projects. Master's Thesis, Norwegian University of Science and Technology, Trondheim, Norway, 2017.

35. Brookes, N.J.; Backhouse, C.J. Understanding concurrent engineering implementation: A case-study approach. Int. J. Prod. Res. 1998, 36, 3035-3054. [CrossRef]

36. Thamhain, H.J. Concurrent engineering for integrated product development. In The Wiley Guide to Managing Projects; Wiley: Hoboken, NJ, USA, 2004; pp. 450-470.

37. Coşkun, H.; Erdiş, E.; Genç, O. Improving the performance of construction projects by employing concurrent engineering. Çukurova Univ. Mühendislik Mimarlık Fakültesi Dergisi 2016, 31, 7-58.

38. Lim, S.; Buswell, R.A.; Le, T.T.; Austin, S.A.; Gibb, A.G.; Thorpe, T. Developments in construction-scale additive manufacturing processes. In Automation in Construction; Elsevier: Amsterdam, The Netherlands, 2012; pp. 262-268.

39. Crowley, A. Construction as a manufacturing process: Lessons from the automotive industry. In Computers E Structures; Elsevier: Amsterdam, The Netherlands, 1998; pp. 389-400.

40. Love, P.E.; Gunasekaran, A. Concurrent engineering in the construction industry. Concurr. Eng. 1997, 5, 155-162. [CrossRef]

41. Anumba, C.J.; Evbuomwan, N.F. Concurrent engineering in design-build projects. Constr. Manag. Econ. 1997, 15, 271-281. [CrossRef]

42. Anumba, C.; Kamara, J.M.; Cutting-Decelle, A.F. Concurrent Engineering in Construction Projects; Routledge: Abingdon, UK, 2006.

43. Zidane, Y.J.; Stordal, K.B.; Johansen, A.; Van Raalte, S. Barriers and challenges in employing of concurrent engineering within the Norwegian construction projects. In Procedia Economics and Finance; Elsevier: Amsterdam, The Netherlands, 2015; pp. 494-501.

(C) 2019 by the authors. Licensee MDPI, Basel, Switzerland. This article is an open access article distributed under the terms and conditions of the Creative Commons Attribution (CC BY) license (http://creativecommons.org/licenses/by/4.0/). 